\title{
REORDENAMENTO INSTITUCIONAL: REFLEXÕES SOBRE ASSESSORIA E FORMAÇÃO AS INSTITUIÇÕES FILANTRÓPICAS DE ASSISTÊNCIA SOCIAL.
}

\author{
Geovana Silva ${ }^{1}$, \\ Edvaldo Roberto Oliveira ${ }^{2}$, \\ Marcio Eduardo Brotto ${ }^{3}$
}

\section{RESUMO}

A política de assistência social, desde 2004, vem sofrendo reformulações significativas, que se refletem na concepção política, em instrumentos normativos e nas estruturas de execução e gestão, o que possibilita caracterizá-la como um campo em permanente transformação. Neste processo, chama atenção à diretriz de adequação das ações assistenciais, em conformidade com a tipificação nacional dos serviços reconhecidos como de assistência social. Este estudo se propõe a uma análise da influência desta normatização no conjunto das instituições filantrópicas que historicamente foram responsáveis pela execução da assistência social no Brasil, refletindo sobre a influência deste reordenamento, a partir da estruturação do Sistema Único de Assistência Social. Envolvendo mestrandos e doutorandos, seu desenvolvimento toma por base a realização de assessoria, desde 2014, junto a 37 instituições filantrópicas, espiritas e católicas, vinculadas ao sistema de proteção social da cidade do Rio de Janeiro.

Palavras-chave: Assistência Social, Filantrópicas, Reordenamento e Tipificação dos Serviços.

\section{ASSISTÊNCIA SOCIAL: ASPECTOS INTRODUTÓRIOS SOBRE UMA POLÍTICA EM TRANSFORMAÇÃO.}

A trajetória da política de assistência social permite verificar que, a partir dos anos de 1980, o movimento de transição democrática e de ruptura com práticas conservadoras, tomando por base sua legitimação enquanto política pública e a formulação de leis específicas para o setor.

Desta forma, inserida no contexto do Estado Democrático, conforme apontado no quadro acima, a Lei Orgânica da Assistência Social (LOAS) reflete, no Brasil, uma nova concepção institucionalizada de assistência social, compreendida como um sistema público vinculado a uma rede socioassistencial integrada por entidades e organizações

\footnotetext{
1 Assistente Social, doutoranda em Serviço Social/PUC-Rio e integrante NIEPSAS - Núcleo Integrado de Estudos e Pesquisas em Seguridade e Assistência Social; Professora Assistente, Membro da Coordenação Social da Pastoral do Menor/Mitra Arquiepiscopal do Rio de Janeiro.

${ }^{2}$ Assistente Social. Mestrando do Programa de Pós-Graduação do Departamento de Serviço Social da PUC-Rio, onde é membro do NIEPSAS - Núcleo Integrado de Estudos e Pesquisas em Seguridade e Assistência Social da PUC-Rio. Especialista em Gestão Social pela Fundação Getúlio Vargas (FGV) e Consultor da CAPEMISA SOCIAL.

${ }^{3}$ Doutor em Serviço Social/PUC-Rio; Professor Assistente, do Quadro Principal, do Departamento de Serviço Social da PUC-Rio; Coordenador do NIEPSAS - Núcleo Integrado de Estudos e Pesquisas em Seguridade e Assistência Social da PUC-Rio.
} 
de assistência social. Por outro lado, abriu espaço para a participação deliberativa da sociedade civil, buscando garantir, também, a necessária articulação e integração com as demais políticas sociais.

Além disso, a assistência social passa a ser definida como um sistema descentralizado e participativo, levando-se em consideração diretrizes tais como: articulação interinstitucional, controle social, comando único, financiamento $\mathrm{e}$ cofinanciamento, instâncias de pactuação, intersetorialidade, níveis de gestão, definição de porte dos municípios, proposição de um protagonismo dos usuários, identificação e determinação de uma rede socioassistencial, atuação tendo por base uma dada territorialidade (LOAS, 1993).

Apesar de estabelecer avanços evidentes, não se pode deixar de registrar que impasses históricos e conjunturais continuam a desafiar o campo da assistência social a estruturar-se como política e consolidar-se como pública (RAICHELIS, 1998).

Nesse sentido, o Brasil, uma década após a aprovação da LOAS, ainda convivia com: (1) a existência de questionamentos sobre a assistência social enquanto política garantidora de direitos, o que decorre da tradição assistencialista, centralizadora e clientelista; (2) dificuldades da garantia e da efetiva inclusão social através de ações da política de assistência social; (3) ausência de avaliação dos impactos da política nas condições de vida da população que demanda seus serviços; (4) incertezas sobre a influência e contribuição de um sistema descentralizado e participativo na construção de estratégias e mecanismos públicos e democráticos de regulamentação e participação/controle social.

Além desses aspectos, as diretrizes e os princípios estabelecidos na legislação brasileira e na Política Nacional de Assistência Social (PNAS) estavam na contramão das medidas neoliberais adotadas nos anos de 1990, reforçando a descontinuidade, focalização e seletividade das iniciativas governamentais. Nesse sentido,

é sempre oportuno lembrar que nos anos de 1990 a somatória de extorsões que configurou um novo perfil para a questão social brasileira, particularmente pela via da vulnerabilidade do trabalho, convive com a erosão do sistema público de garantias e proteções sociais e com a emergência de "modernas" práticas filantrópicas que despolitizam os conflitos sociais e confrontam-se com a universalidade das políticas sociais públicas (YAZBEK, 2004, p. 12).

Diante do exposto, vale destacar que a capacidade de execução e consolidação da LOAS continua a depender das relações políticas, técnicas e operacionais estabelecidas entre as diferentes esferas de governo durante a sua implementação.

Dessa forma, o momento atual expressa o esforço de reconceituação e consolidação de uma "identidade" para a política de assistência social, iniciado em 1993, quando da promulgação da LOAS, e reafirmada em 2004 por intermédio da PNAS que, regulamentada pela Norma Operacional Básica de 2005 (NOB 2005), instituiu o Sistema Único de Assistência Social (SUAS), recentemente regulamento pela Lei 12.435 de 06 de junho de 2011 .

O SUAS é definido como "um sistema público não contributivo, descentralizado e participativo que tem por função a gestão do conteúdo especifico da assistência social no campo da proteção social brasileira" (NOB 2005). Portanto, configura-se como uma ferramenta de gestão da Política Nacional de Assistência Social, que estabelece como 


\section{SEMINÁRIO DE PESQUISA EM CIÊNCIAS HUMANAS - SEPECH \\ Humanidades, Estado e desafios didático-científicos \\ Londrina, 27 a 29 de julho de 2016}

funções da assistência social a proteção social hierarquizada em Básica e Especial, a vigilância social e a defesa dos direitos socioassistenciais, que devem ser tratadas de forma articulada, estabelecendo interseções contínuas e fortalecendo o sistema como um todo - na lógica representada abaixo:

Considerando essas funções, mas também objetivando ampliar a organização democrática da Política de Assistência Social com o fortalecimento das diretrizes expressas na Constituição Federal e na LOAS, a gestão do SUAS pauta-se nos seguintes eixos estruturantes: (1) precedência da gestão pública da política; acesso aos direitos sócio-assistenciais pelos usuários; (2) matricialidade sócio-familiar; (3) territorialização; (4) descentralização político-administrativa; (5) financiamento partilhado entre os entes federados; (6) fortalecimento da relação democrática entre Estado e sociedade civil; (7) valorização do controle social e, por conseguinte, da participação popular; (8) qualificação de recursos humanos e (9) informação, monitoramento, avaliação e sistematização de dados e resultados.

A intenção é de que articulação entre esses eixos permita a construção de uma rede de proteção social fortalecida e organizada em níveis de complexidade, capazes de atender as demandas caracterizadoras de diferentes níveis de vulnerabilidade. A figura abaixo apresenta um esquema desses níveis:

Para a implementação dos considerados eixos estruturantes do SUAS, foram definidas as responsabilidades das três esferas de governo na execução da PNAS, objetivando o fortalecimento de uma gestão articulada no âmbito do pacto federativo. Nesse sentido, considerando o grande número de municípios, bem como as diversidades regionais, o SUAS estabeleceu modelos de gestão (inicial, básico ou pleno) baseados na capacidade de cada cidade em executar ações e estabelecer o cofinanciamento dos serviços na área da assistência social.

Portanto, o SUAS busca enfatizar a descentralização e a recomposição do campo sócio-assistencial, reordenando a estrutura organizacional da assistência social. Esta deve funcionar como uma rede de proteção social, com o objetivo de articular e integrar ações e recursos, tanto nas relações endógenas das instituições, como no campo interinstitucional e na articulação com os diferentes conselhos setoriais e de direitos.

Nesse sentido, "ao invés de substituir a ação do Estado, a rede deve ser alavancada a partir de decisões políticas tomadas pelo poder público em consonância com a sociedade" (PNAS, 2004, p.41).

Nesse contexto, as Normas Operacionais Básicas (NOB's) desempenharam papel de relevância na superação de correntes e metodologias conservadoras e, assim, foram fundamentais para o estabelecimento de uma verdadeira política de assistência social. Em específico, a NOB 2005, ora em vigor, estabelece a modalidade de gestão pública da assistência social a ser exercida pelos entes federados em todo o território brasileiro. De acordo com a mesma, ficam estabelecidas as características do Sistema Único de Assistência Social, as funções da política para ampliação da proteção social brasileira e os níveis e tipos de gestão do SUAS. Por outro lado, também ganha visibilidade as diretrizes sobre o financiamento da política de assistência social, bem como as instâncias de articulação, deliberação e pactuação da gestão democrática do sistema, com finalidade de operacionalizar conquistas em meio a um contexto de frequentes embates entre Estado e da Sociedade Civil.

Pautado na organização acima, fica explicito que a PNAS e, por conseguinte o SUAS, definem instâncias e mecanismos de articulação, pactuação e deliberação, que 
regulamentados pela Norma de Orientação Básica 2005 (NOB 2005), possuem a finalidade de ampliar a participação dos segmentos sociais e institucionais, interessados e envolvidos na tomada de decisões no campo da política de assistência social, de modo a garantir transparência ao conjunto de negociações. Esses segmentos envolvem desde instâncias articuladoras (de organização dos movimentos e entidades que integram o sistema) às instâncias deliberativas, pautadas em espaços formalmente instituídos como decisórios nas três esferas de governo. Além dessas, torna-se necessário indicar a existência de instâncias de pactuação, que são responsáveis pela articulação entre representações das diferentes esferas de governo e pela definição de ações e medidas por elas compartilhadas no conjunto do sistema - cuja participação, também, permite verificar a existência de práticas ainda direcionadas à centralização política na tomada de decisões.

A necessidade de operacionalização do SUAS e da Política Nacional de Assistência Social (PNAS), no nível municipal, apresenta diversos desafios, dentre os quais o de investir em múltiplas formas de capacitação e atualização de seus gestores e operadores, assim como dos dirigentes e trabalhadores das organizações sociais prestadoras de serviço que contribuem, de forma complementar, na rede socioassistencial. Da mesma forma, deve-se buscar a criação de espaços de reflexão sobre a implementação dessa política no nível local, tentar superar a fragmentação das ações, o que implica pensar a operacionalização de seu conteúdo intersetorial, e, por fim, promover a avaliação contínua de seus resultados.

Todos esses aspectos configuram as especificidades e complexidades do campo da assistência social, que tem o desafio de implementar suas diretrizes de forma homogênea, num país repleto de diversidades, superando a influência da lógica tecnocrática. Ao mesmo tempo, presencia-se, no campo da assistência social, caracterizado por definições mais fluidas e complexas, o esforço de consolidar um sistema único que, contudo, demarca uma excessiva semelhança com o da área da saúde.

Essa perspectiva de valorização da política de assistência social confronta-se com realidades municipais marcadas por histórias políticas distintas, que conformam uma leitura da assistência social como um campo permeado por valores, crenças e missões; frequentemente utilizado como base de sustentação de poderes políticos e institucionais locais, o que revela que essa cultura política conservadora funciona como um entrave para a construção democrática da política de assistência social brasileira.

\section{MARCOS LEGAIS E A DIRETRIZ DE REORDENAMENTO: A BUSCA POR QUALIFICAÇÃO DO QUE DE FATO SEJA ASSISTÊNCIA SOCIAL}

Historicamente, há uma predominância de que a assistência vai se estruturando nas relações com a sociedade civil e no interior do Estado, configurando-se em práticas muitas vezes pontuais, descontinuadas, com recursos escassos. Desta forma, O Estado contribui para que a assistência social transitasse sempre no campo da solidariedade, filantropia, e benemerência. Ou seja, uma área pautada em princípios que nem sempre representam direitos sociais, mas apenas benevolência paliativa. Porém a partir do momento em que a mesma se configura como política pública exige responsabilidade, 


\section{SEMINÁRIO DE PESQUISA EM CIÊNCIAS HUMANAS - SEPECH \\ Humanidades, Estado e desafios didático-científicos \\ Londrina, 27 a 29 de julho de 2016}

compromisso e orçamento próprio, o que só virá acontecer no Brasil com a efetivação da Constituição Federal de 1988.

A promulgação em dezembro de 1993, da Lei Orgânica da Assistência Social (LOAS), que posteriormente, em 2011, veio a ter alterações da Lei 12.435, e em 2004, o Serviço único de Assistência Social $S U A S$ e da Política Nacional de Assistência social (PNAS), a Tipificação 109 em 2009, em 2009 a Lei 12.101 da Filantropia, e em 2013, a Lei $\mathrm{n}^{\circ} 12868 / 2013$, que, entre outras coisas, altera a Lei $\mathrm{n}^{\circ} 12.101 / 2009$ (Lei da Filantropia) a alteração dessa lei visam principalmente simplificar e adequar o processo de certificação das entidades sem fins lucrativos que prestam serviços nas áreas da saúde, da educação e da assistência social. Estes marcos regulatórios visam requerer uma nova concepção de assistência social como política pública, dever de Estado e o direito do cidadão.

Além disso, aprofunda o debate, suprimir a cultura paternalista, voluntarista e populista, dar-lhe um caráter profissional, favorecendo, ainda, a implantação de mecanismo de controle social e a transparência de informações entre as esferas de governo e a sociedade civil.

A trajetória de 20 anos de promulgação da LOAS, traz no seu bojo debates de avanços, limites e perspectivas apresentadas na implementação do atual SUAS, como modelo público de assistência social, descentralizado, participativo, socialmente controlado com comando único, sob a responsabilidade primaz Estado.

Desse modo, a gestão da política pública de assistência social compreende muitos desafios. Envolve uma complexidade de demandas, questionamentos de práticas seculares e clama por novas interlocuções.

Dados divulgados pela Pesquisa Fundações Privadas e Associações sem fins Lucrativos (FASFIL/2014) indicam que existem no Brasil 290.7 mil organizações da sociedade civil. A maior parte delas surgiu após a promulgação da Constituição Federal de 1988, que reconheceu a organização e a participação social como direitos e valores a serem garantidos e fomentados.

Paralelamente, foi sancionado no Congresso Nacional brasileiro o projeto de lei sobre O Marco Regulatório das Organizações da Sociedade Civil que é uma agenda Política ampla que tem como objetivo aperfeiçoar o ambiente jurídico e institucional relacionado às organizações da sociedade civil e suas relações de parceria com o Estado.

As ações do Marco Regulatório são parte da agenda estratégica do governo federal que, juntamente com a sociedade civil, define três eixos orientadores: contratualização, sustentabilidade econômica e certificação. Esses temas são trabalhados tanto na dimensão dos projetos de lei, decretos, portarias, quanto na dimensão do conhecimento, estudos e pesquisas, seminários, publicações, cursos de capacitação e disseminação de informações sobre o universo das organizações da sociedade civil.

O Marco Regulatório das Organizações da Sociedade Civil estabelece novas regras para as entidades privadas sem fins lucrativos, ou seja, às associações e fundações criadas em torno de desejos e objetivos comuns, que desenvolvem ações de interesse público e não têm o lucro como objetivo. São as organizações que atuam na promoção de direitos e de atividades nas áreas de saúde, educação, cultura, ciência e tecnologia, desenvolvimento agrário, assistência social, moradia, entre outras

As entidades filantrópicas se configuram no cenário brasileiro como coadjuvantes para o desenvolvimento e operacionalização da Política Nacional de Assistência Social, compondo a Rede Socioassistencial Privada, sendo parceiras, ou ainda, conveniadas do 
Estado no desenvolvimento dos programas, projetos e serviços no campo social. A nossa realidade social é marcada por uma crescente desresponsabilização ou refilantropização do Estado e a responsabilização e participação da sociedade civil no trato das expressões da Questão Social.

A relevância da constituição de uma rede de serviços socioassistenciais se deve em virtude da história das políticas sociais do Brasil, principalmente de Assistência Social, que traz no seu bojo a cultura política do assistencialismo e da benemerência, marcada pela lógica ineficaz da diversidade, fragmentação, descoordenação, sobreposição e paralelismo das ações, entidades e órgãos, além de dispersão de recursos humanos, financeiros e materiais. Nestas condições, é imprescindível formar redes, espaços de colaboração, participação em ações integradas de modo a multiplicar chances de aproximar nossas conquistas legais no campo da legislação das praticas do Estado e das práticas pedagógicas das instituições da sociedade civil parceiras do Estado na execução da referida política pública, como direito social.

Diante dos marcos legais da Assistência Social no Brasil, algumas Entidades filantrópicas do município do Rio de Janeiro, foram impactadas com a legislação a partir da Constituição de 1988, devendo haver no processo o reordenamento institucional, procurando enfocar as mediações teóricas e históricas presentes nas políticas sociais e nos sujeitos coletivos primando ações pautadas nos direitos sociais e não no assistencialismo e os desafios enfrentados objetivando a transformação societária.

\section{O Assessoramento às Instituições Espíritas e Católicas: a experiência da interlocução entre PUC-Rio, CAPEMISA Social e Arquidiocese do Rio de Janeiro.}

Com base em um termo de cooperação técnica institucional, o Departamento de Serviço Social da PUC Rio, em parceria a Arquidiocese do Rio de Janeiro e a Capemisa Social, desde março de 2014, vem realizando assessoramento às instituições católicas e espíritas que atuam no âmbito da política de assistência social, realizando neste período Capacitação para Elaboração de Relatório de Atividades e o Plano de Ação institucional, para solicitação de manutenção do reconhecimento institucional como promotora de assistência social, conforme a Lei n ${ }^{\mathrm{o}}$ 12.101, de 27 de novembro de 2009.

Da mesma forma, com o objetivo de assessorar as Instituições, para possibilitar a adequação das ações sociais desenvolvidas, conforme prevê a Resolução ${ }^{\circ}$ 27, de 19 de setembro de 2011 que altera parâmetros nacionais da Resolução $n^{\circ} 16$, de 05 de maio de 2010, que estabelece os objetivos de seus programas, projetos e benefícios socioassistenciais em consonância com o conjunto normativo da Política Nacional de Assistência Social.

Neste sentido, Aldaíza Sposati (2004) afirma que a implantação do SUAS exige romper com a fragmentação pragmática; exige separar o paralelismo de responsabilidades entre as três esferas de governo; exige ainda, construir referências sobre a totalidade de vulnerabilidades e riscos sociais superando a vertente de análise segregadora em segmentos sociais, sem compromisso com a cobertura universal e o alcance da qualidade dos resultados.

Participaram deste processo, trinta e sete (37) instituições filantrópicas, espiritas e católicas, vinculadas ao sistema de proteção social da cidade do Rio de Janeiro, 


\section{SEMINÁRIO DE PESQUISA EM CIÊNCIAS HUMANAS - SEPECH \\ Humanidades, Estado e desafios didático-científicos \\ Londrina, 27 a 29 de julho de 2016}

representadas pelos seus gestores (25) e/ou técnicos (12). Apresentaremos nesta sistematização, aspectos demarcados pelos gestores, entendendo serem eles os que mantem maior resistência às mudanças decorrentes de uma nova forma de pensar e organizar a política de Assistência Social, conforme as diretrizes do SUAS.

Neste sentido, um primeiro aspecto que se buscou levantar, condiz ao tempo de trabalho e vinculação do gestor à instituição. Verificamos conforme, gráfico 01, que $36 \%$ dos gestores atuam na instituição por mais de vinte anos (20), demonstrando tendências à cristalização de práticas e concepções que demarcam características da cultura politica na assistência social.

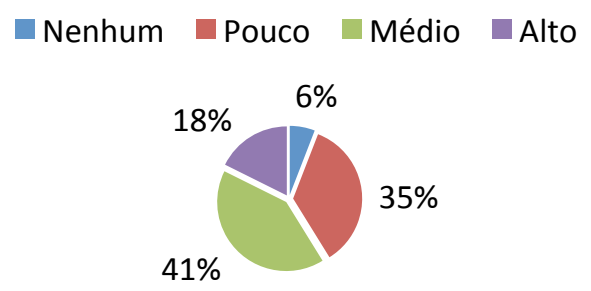

Gráfico 01: Tempo Institucional de Atuação dos Gestores

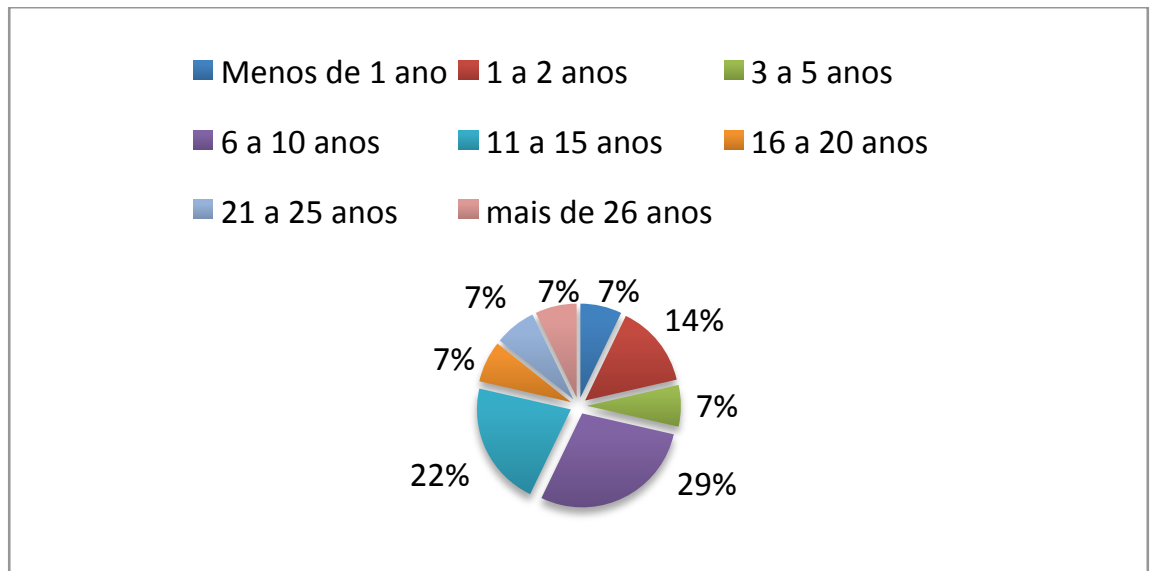

Gráfico 02: grau de conhecimento em relação à nova concepção de Assistência Social

Isso acaba por se refletir na capacidade de compreensão e entendimento acerca das mudanças legais, estruturais e conceituais em vigência no campo da assistência social, evidenciando-se, conforme gráfico 02 , que mais de $40 \%$ tem pouco, ou nenhum, conhecimento sobre este processo. Este percentual aumenta para $65 \%$ quando indagamos sobre este conhecimento em relação às atribuições e competências das 03 esferas de governo.

Consequentemente, essa ausência de conhecimento também se reflete na sua capacidade de interlocução nos espaços de controle social como conselhos e conferências, onde $64 \%$ dos gestores da rede filantrópica desconhecem ou participam muito pouco desses espaços, o que dificulta inclusive o entendimento sobre o reordenamento institucional e as normatizações ou orientações que os conselhos devem repassar as instituições, que solicitam inscrição e reconhecimento na assistência social. 


\section{SEMINÁRIO DE PESQUISA EM CIÊNCIAS HUMANAS - SEPECH \\ Humanidades, Estado e desafios didático-científicos \\ Londrina, 27 a 29 de julho de 2016}

Ainda em relação à participação nos conselhos, demarcamos que sua dinâmica torna-se fundamental para reconhecimento e fortalecimento da rede socioassistencial. Neste campo verificamos que a ausência de efetivo conhecimento da política nacional de assistência social e suas estruturas, por parte das entidades. Nesta abordagem inicial, foi possível verificar que $59 \%$ dos gestores afirmam possuir pouco ou nenhum conhecimento sobre o papel dos Centros de Referência da Assistência Social (CRAS) e $50 \%$ desconhecimento sobre o Centro de Referência Especializado de Assistência Social (CREAS) - instâncias públicas centrais na execução da política de assistência social contemporânea.

Neste contexto, o processo de reordenamento institucional no campo da assistência social converge para deliberações de um conjunto de legislações, com destaque para a Lei Orgânica da Assistência Social (LOAS), considerada de pouco conhecimento para 55\% dos gestores. Com a implantação do SUAS, outras somam-se, com destaque para a Tipificação Nacional de Serviços Socioassistenciais, publicizada pela resolução 109 do Conselho Nacional de Assistência Social (CNAS), desconhecida por 56\% dos gestores. Outra importante legislação para o debate institucional relacionase a promulgação da Lei 12.101/2009, também conhecida como Lei da Filantropia, de pouco ou nenhum conhecimento para $45 \%$ dos gestores. Por fim, verificamos ainda que, conforme gráfico 03, 69\% dos gestores desconhecem, ou pouco sabem, sobre o Plano Nacional de Promoção, Proteção e Defesa do Direito de Crianças e Adolescentes à Convivência Familiar e Comunitária (PNCFC), apesar de 65\% afirmarem desenvolver ações em consonância com o mesmo - vinculando o papel de conhecê-lo aos técnicos de suas instituições.

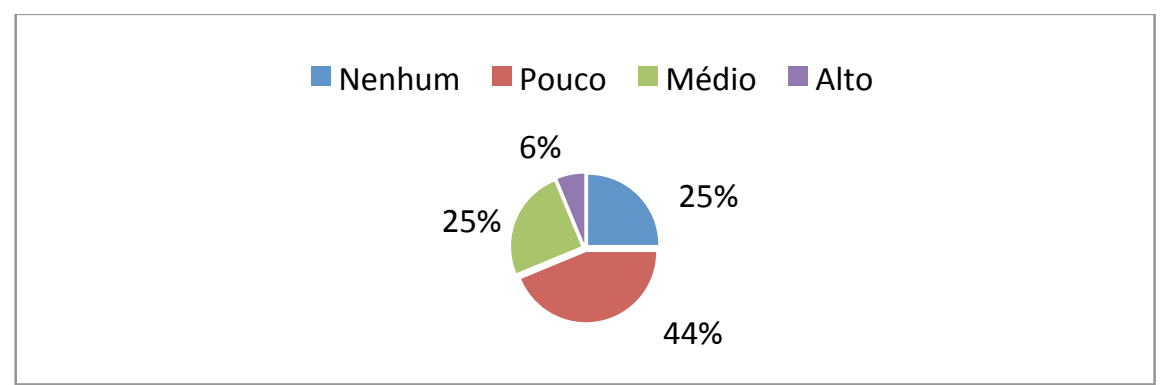

Gráfico 03: Conhecimento sobre o Plano Nacional de Promoção, Proteção e Defesa do Direito de Crianças e Adolescentes à Convivência Familiar e Comunitária.

Esses aspectos legais nos levaram apensar e a querer reconhecer características da gestão dos serviços socioassistenciais ofertados por estas instituições católicas e espíritas. Neste sentido, verificamos que $88 \%$ dos gestores afirmam já terem experiências e participação na realização de planejamentos institucionais, coma definição de metas a serem alcançadas de modo estratégico: a curto, médio e longo prazo. Porém, conforme expressa o gráfico $04,73 \%$ estão entre os que sinalizam saberem pouco ou nada sobre as ferramentas de sua elaboração, o que melhor contribuiria para a execução e o alcance dos objetivos institucionais - segundo $63 \%$ dos gestores. 


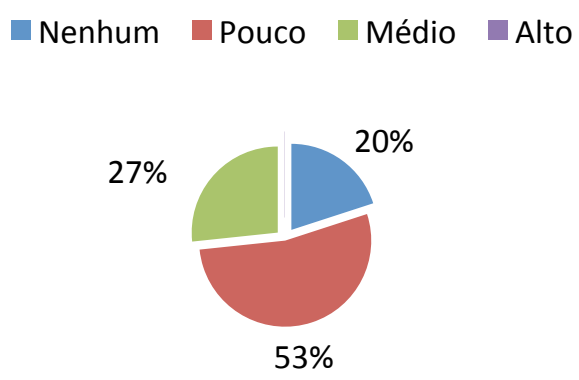

Gráfico 04: Grau de conhecimento sobre planejamento estratégico situacional

Diante desses aspectos iniciais, verificamos que o processo de reordenamento da política de assistência social e suas diretrizes, necessitam de investimentos fundamentais na educação permanente de gestores e profissionais, em busca de maior eficiência no planejamento e na execução das ações junto ao conjunto de serviços oferecidos a população demandatária.

\section{CONSIDERAÇÕES FINAIS}

Diante do exposto, temos que pensar que as entidades possuem tradições, cada instituição trabalha com seus valores, princípios, daí a sutileza de entendermos como relacioná-los com a legislação vigente. É um desafio viver esse processo de transição para as entidades e também para os conselhos de direito. É fundamental neste processo que as entidades tenham clareza da sua identidade institucional, que é constituída a partir do grau de conhecimento que os mesmos têm das relações políticas, sociais e religiosas vigentes no contexto atual.

Participar da implementação da política pública de assistência social permite aproximar e construir com as entidades os caminhos que devem ser trilhados e que vão além das questões legalistas. É fundamental considerar a singularidade do outro na relação de respeito e corresponsabilidade, possibilitando perceber o potencial de cada membro que constitui a rede socioassistencial pública e/ou privada. Neste processo é importante que não ocorra uma desqualificação ou fragmentação das ações, da mesma forma que se supere o desconhecimento do trabalho institucional - devendo-se sinalizar que muitas das vezes o próprio Estado negligencia e ou não cumpre a legislação.

Frente a isto, a relevância do momento histórico da Assistência Social, em relação às entidades como se adequar aos novos tempos sem deixarem de ser quem são no nível da identidade institucional, não desconectando o real do ideal. É necessário à mudança, o reordenamento acompanhado de uma visão e ação de processo, capaz de desenvolver ações planejadas, continuadas, públicas e/ou compartilhadas com a rede privada.

\section{REFERÊNCIAS BIBLIOGRÁFICAS}

BRASIL. Lei Orgânica de Assistência Social. Lei no 8.742, de 7 de dezembro de 1993, publicada em D.O.U de 08 de dezembro de 1993. 


\section{SEMINÁRIO DE PESQUISA EM CIÊNCIAS HUMANAS - SEPECH \\ Humanidades, Estado e desafios didático-científicos \\ Londrina, 27 a 29 de julho de 2016}

Ministério da Administração Federal e Reforma do Estado. Plano Diretor da Reforma do Aparelho do Estado. Brasília, 1995.

. Ministério do Desenvolvimento Social - MDS/CNAS. História da Política de Assistência Social. Texto produzido para capacitação de conselheiros estaduais e municipais de assistência social. Brasília, 2000.

- Norma Operacional Básica de Recursos Humanos do Sistema Único de Assistência Social - NOB RH/SUAS. Ministério do Desenvolvimento Social e Combate à Fome/Secretaria Nacional de Assistência Social. Brasília - DF, dezembro de 2006.

. Desafios da Gestão do Sistema Único de Assistência Social nos Municípios e Estados. Caderno 03. Ministério do Desenvolvimento Social. Brasília, 2007.

MOTA, Ana Elizabete. O mito da Assistência Social - ensaios sobre Estado, política e sociedade. São Paulo, Cortez, 2008.

PAOLI, Maria Célia e TELLES, Vera da Silva. Direitos Sociais: Conflitos e negociações no Brasil Contemporâneo. In: Cultura e Política nos Movimentos Sociais Latino-Americanos. Novas Leituras, 2000.

RAICHELIS, R. Esfera pública e conselhos de assistência social: caminhos da construção democrática. São Paulo: Cortez, 1998.

SPOSATI, Aldaíza. Modelo Brasileiro de Proteção Social não contributiva: concepções fundantes. Oficinas e Seminário sobre Seguridade Social. PUC-Rio, 2013. 